\title{
Fermentative Production of Lactic Acid as a Sustainable Approach to Valorize Household Bio-Waste
}

\author{
Panagiotis Tsapekos ${ }^{1 \neq}$, Merlin Alvarado-Morales ${ }^{1 \neq}$, Samin Baladi ${ }^{1,2}$, Elleke F. Bosma ${ }^{3 \dagger}$ and \\ Irini Angelidaki ${ }^{1 *}$
}

${ }^{1}$ Department of Environmental Engineering, Technical University of Denmark, Lyngby, Denmark, ${ }^{2}$ Department of Biosystem Engineering, Faculty of Agriculture, Shahid Chamran University of Ahvaz, Ahvaz, Iran, ${ }^{3}$ The Novo Nordisk Foundation Center for Biosustainability, Technical University of Denmark, Lyngby, Denmark

\section{OPEN ACCESS}

Edited by:

Rajib Mukherjee,

University of Texas of the Permian

Basin, United States

Reviewed by:

Yogendra Shastri,

Indian Institute of Technology

Bombay, India

Andres Fernando Barajas Solano,

Francisco de Paula Santander

University, Colombia

${ }^{*}$ Correspondence: Irini Angelidak

iria@env.dtu.dk

${ }^{\dagger}$ Present address: Elleke F. Bosma,

Discovery, R\&D, Chr. Hansen A/S,

Bøge Allé, Hørsholm, Denmark

¥These authors have contributed equally to this work

Specialty section:

This article was submitted to Sustainable Chemical Process Design,

a section of the journal

Frontiers in Sustainability

Received: 14 May 2020

Accepted: 29 July 2020

Published: 08 September 2020

Citation:

Tsapekos P, Alvarado-Morales M,

Baladi S, Bosma EF and Angelidaki I (2020) Fermentative Production of

Lactic Acid as a Sustainable

Approach to Valorize Household Bio-Waste. Front. Sustain. 1:4 doi: 10.3389/frsus.2020.00004
Source-sorted organic portion of municipal solid waste (bio-waste) can be fermented to lactic acid, a platform chemical widely used in the production of biodegradable polymers, green solvents, and chemicals. In the present study, fermentation of bio-waste using lactic acid producing bacterium (LAB) Lactobacillus delbrueckii was investigated. Results showed that adding 10\% (v/v) of $L$. delbrueckii as LAB inoculum along with $\mathrm{pH}$ adjustment to 6.2 had the highest lactic acid yield ( $\left.0.65 \mathrm{~g} / \mathrm{g}_{\text {total sugars }}\right)$. Nevertheless, $\mathrm{pH}$ adjustment without bio-augmentation could also result in relatively high yield of lactic acid $\left(0.57 \mathrm{~g} / \mathrm{g}_{\text {total sugars }}\right)$. Furthermore, enzymatic hydrolysis was applied to boost the lactic acid production slightly increasing the yield to $0.72 \mathrm{~g} / \mathrm{g}_{\text {total }}$ sugars. Thus, fermentative production of lactic acid can be achieved without the addition of enzymes to reduce production costs. Overall, the results indicate that bio-waste could be a suitable substrate for the production of lactic acid.

Keywords: Lactobacillus delbrueckii, fermentation, lactic acid, bio-waste, enzymatic hydrolysis

\section{INTRODUCTION}

Lactic acid (LA) or 2-hydroxypropionic acid is the simplest hydroxycarboxylic acid and perhaps the most widely occurring in nature. LA is a chiral molecule with two optical active isomeric forms (known as "enantiomers"): the dextrorotatory form L(+)-lactic acid or (S)-lactic acid, and the levorotatory form, D(-)-lactic acid or (R)- lactic acid (Mora-Villalobos et al., 2020). Due to the presence of two reactive functional groups -one hydroxyl $(-\mathrm{OH})$ and one carboxyl ($\mathrm{COOH}$-lactic acid can undergo a variety of chemical conversions to produce e.g., acrylic acid (via dehydration), 1, 2-propanediol (via hydrogenation), acetaldehyde (via decarboxylation), 2, 3pentanedione (via condensation), and poly lactic acid (PLA). LA can be produced via chemical or microbial fermentation routes. A racemic mixture of D-LA and L-LA (50:50) is obtained via chemical synthesis, which is not desirable for food, beverage, and pharmaceutical applications. Furthermore, LA of high optical purity (e.g., over $98-99 \%$ of L-LA) is required for the production of PLA. The fermentative route offers several advantages over the chemical synthesis such as simple operation, utilization of low-cost renewable feedstocks, mild pressure and temperature conditions and reduced risk of contamination, low energy consumption, and better environmental performance (Alves de Oliveira et al., 2018; Singhvi et al., 2018).

Moreover, when an appropriate LA producer is used in the fermentation process is possible to produce either D-LA or L-LA with high optical purity (Abdel-Rahman et al., 2013). At present, 
almost all LA is produced at commercial scale by bacterial fermentation of starch-derived glucose having a negative impact on the food supply chain -using homofermentative lactic acid bacteria (LAB) (Singhvi et al., 2018). Among the various LA producers the LAB Lactobacillus delbrueckii is commonly applied in industrial processes as is able to produce the D-enantiomer (Bosma et al., 2017). LA fermentation performance-as any other fermentation process-is evaluated by product yield, productivity and titer parameters, whilst usually parameters such as substrate, nutrient utilities and downstream processing costs, respectively, drive the economy of the process. One of the core aims in LA production via fermentative route is to reduce the cost of substrates and improve productivity.

Starchy materials such as corn, maize, rice, wheat, potato, barley, and cassava are in general good substrates for LA production; but they need to be pretreated by physicochemical methods and amylolytic enzymes prior to fermentation. Moreover, the use of these feedstocks for LA production imposes the competition of LA industry vs. food sector as these are used for human and animal feeding as well. Lignocellulosic materials such are sawdust, poplar trees, sugar cane bagasse, brewer-spent grains, etc., are the most promising feedstocks for LA production due to they are abundant, potentially inexpensive, have a high carbohydrate content and they do not outcompete with the food chain supply. However, the main challenge is to break down the polymeric matrix into fermentative sugars. This is because lignocellulosic materials content cellulose as its main component, which is a recalcitrant polymer and its second abundant component, hemicellulose which is a polymer formed by monomeric units of xylose and arabinose, which cannot be metabolized by the majority of LAB (Alves de Oliveira et al., 2018). Thus, the need of harsh pretreatments followed by enzymatic hydrolysis makes the whole process cost-inefficient. Overall, the cost of pretreatment is the common bottleneck associated with these feedstocks, as most of LAB cannot use them directly for LA production. Thus, the use of inexpensive feedstocks-such as food waste and/or municipal bio-wastewhose pretreatment requirements are minimal can contribute to offset the LA production cost. On the other hand, within the frame of circular economy, novel approaches relying on recycling and/or reuse of "organic wastes" for LA production are therefore necessary.

To this respect, attempts to produce LA from low-cost organic wastes have been reported in recent years. Tang et al. (2016) reported the use of food waste for LA production. The effect of $\mathrm{pH}$, temperature, and organic loading rate in the indigenous microbiota were investigated with the aim to enhance LA production. High-throughput pyrosequencing analysis revealed that Lactobacillus sp.- - present in the raw food waste-were the dominant species of the indigenous microbiota and these played a key role in LA fermentation performance facilitating high lactic acid productivity. Pleissner et al. (2017) investigated the use of mixed restaurant food waste based on simultaneous saccharification and fermentation (SSF) for LA production. Unlike Tang et al. work, here the authors used Lactobacillus sp. or Streptococcus sp. strains to target the production of L(+)-lactic acid form. or Streptococcus sp. showed a better performance compared to Lactobacillus sp. as was able to efficiently liquefied the food waste converting directly the sugars and nutrients into LA without significant by product formation. Li et al. (2018) reported the use of thermal pretreated food waste in co-fermentation of waste sludge to enhance LA production. Proper thermal pretreatment showed a positive effect on LA production due to the acceleration of solubilization and hydrolysis of carbohydrates. Moreover, changes in the microbial community structure with respect to key microorganisms such as Bacillus sp. and Lactobacillus sp. were linked to the thermal pretreatment conditions.

To this respect, municipal bio-waste is rich in sugars, protein, and lipids, and thus it could be a promising feedstock for lactic acid production (Probst et al., 2013; Tashiro et al., 2013). In addition to the different strategies aforementioned to enhance LA production, "bioaugmentation" which is the addition of specific microbial functional groups into a system to enhance the bioactivity of the entire microbial community (Li et al., 2017), could be a promising strategy to enhance the LA productivity from municipal bio-waste. Bioaugmentation has proven to increase methane production during anaerobic digestion of complex organic substrates and to recover systems operating under inhibited steady state (Tian et al., 2019).

In the present study, Lactobacillus delbrueckii was selected as bioaugmentative microorganism due to its high tolerance to acidic $\mathrm{pH}$, high salt, and ethanol concentrations (Bosma et al., 2017). These properties can be of great aid for the fermentative LA production from municipal bio-waste as this can present the aforementioned adverse characteristics. The aim of this study was to investigate the exploitation of household bio-waste for lactic acid production. Various strategies such as bioaugmentation, $\mathrm{pH}$ adjustment, enzymatic hydrolysis, autoclavation, and their combinations were investigated to elucidate the impact on fermentation conditions that can lead to high lactic acid productivity and yield.

\section{MATERIALS AND METHODS}

\section{Bio-Waste}

The substrate was a mixture of source-sorted organic fraction of municipal solid waste, supermarket waste and food residues from restaurants, large kitchens and cafes. After collection, the urban bio-waste was pretreated with a pulper (HCS A/S Transport \& Shipping, Copenhagen) to disrupt the organic fraction and sort out the non-degradable materials (e.g., plastics, metals etc.) without alternating substrate's chemical composition. Two samples of bio-waste were collected during spring and summer 2018 to define seasonal variation. For the present experiment, the substrates were diluted (1:1) with tap water to prevent clogging, and stored in plastic bottles at $-20^{\circ} \mathrm{C}$ until usage. Table 1 summarizes the characteristics of the diluted substrates.

\section{Microorganisms and Cultivation Medium}

Lactobacillus delbrueckii DSM 20074 was used in the current study. The strain was initially inoculated from glycerol stock $(1 \mathrm{~mL})$ and grew overnight for $24 \mathrm{~h}$ in $20 \mathrm{~mL}$ flasks at a concentration of $10 \%(\mathrm{v} / \mathrm{v})$, containing $19 \mathrm{~mL}$ of sterilized MRS 
TABLE 1 | Characteristics of bio-waste used in this study.

\begin{tabular}{|c|c|c|c|}
\hline Parameter & Unit & 1st bio-waste & 2nd bio-waste \\
\hline TS & $g / L$ & $89.42 \pm 0.52$ & $93.81 \pm 0.50$ \\
\hline VS & $g / L$ & $80.36 \pm 0.55$ & $82.91 \pm 0.51$ \\
\hline $\mathrm{pH}$ & - & 5.24 & 5.05 \\
\hline TKN & g-TKN/L & $4.67 \pm 0.03$ & $4.7 \pm 0.05$ \\
\hline COD & $\mathrm{g}-\mathrm{O}_{2} / \mathrm{L}$ & 255.84 & 240.02 \\
\hline Total VFA & $\mathrm{mg} / \mathrm{L}$ & 2666.05 & 5023.64 \\
\hline Total carbohydrate & $g / L$ & 18.42 & 17.69 \\
\hline Glucose & $g / L$ & $0.48 \pm 0.1$ & $2.86 \pm 0.16$ \\
\hline Xylose & $g / L$ & $2.49 \pm 1.7$ & $0.32 \pm 0.02$ \\
\hline Formic acid & $g / L$ & $2.4 \pm 0.03$ & $3.4 \pm 0.8$ \\
\hline Lactic acid & $g / L$ & $4.72 \pm 0.4$ & $5.75 \pm 0.3$ \\
\hline Acetic acid & $g / L$ & $1.46 \pm 1.99$ & $1.81 \pm 0.25$ \\
\hline Propionic acid & $g / L$ & $0.028 \pm 0.01$ & $0.032 \pm 0.18$ \\
\hline 1-propanol & $g / L$ & $0.014 \pm 0.005$ & $0.0201 \pm 002$ \\
\hline Ethanol & $g / L$ & $2.26 \pm 0.28$ & $3.25 \pm 0.20$ \\
\hline Butyrate & $g / L$ & $0.026 \pm 0.002$ & $0.030 \pm 0.001$ \\
\hline Isobutyrate & $g / L$ & $0.02 \pm 0.01$ & $0.03 \pm 0.12$ \\
\hline $\mathrm{Al}$ & $\mathrm{mg} / \mathrm{TS}$ & 248.5 & 352.5 \\
\hline $\mathrm{Ca}$ & $\mathrm{mg} / \mathrm{TS}$ & 9774.5 & 9766 \\
\hline K & $\mathrm{mg} / \mathrm{TS}$ & 4339.5 & 5026 \\
\hline $\mathrm{Mg}$ & $\mathrm{mg} / \mathrm{TS}$ & 640.5 & 691 \\
\hline $\mathrm{Na}$ & $\mathrm{mg} / \mathrm{TS}$ & 2637.5 & 2562.5 \\
\hline$P$ & $\mathrm{mg} / \mathrm{TS}$ & 1284.5 & 1412 \\
\hline S & $\mathrm{mg} / \mathrm{TS}$ & 939.5 & 1034.5 \\
\hline $\mathrm{Sr}$ & $\mathrm{mg} / \mathrm{TS}$ & 36.5 & 39 \\
\hline $\mathrm{Fe}$ & $\mathrm{mg} / \mathrm{TS}$ & 336.5 & 477.5 \\
\hline
\end{tabular}

TS, Total solids; VS, Volatile solids, TKN, Total Kjeldahl nitrogen; COD, Chemical oxygen demand; VFA, Volatile fatty acids.

broth $\left(121^{\circ} \mathrm{C}, 20 \mathrm{~min}\right)$ and was placed at $37^{\circ} \mathrm{C}$. For the next generation $(10 \mathrm{~mL})$, of the culture was inoculated to $250 \mathrm{~mL}$ serum bottles with a working volume of $100 \mathrm{ml}$, under the same conditions as the first generation ( $90 \mathrm{~mL}$ of MRS). The initial $\mathrm{pH}$ in all flasks was 6.2. The MRS medium contained the following $(\mathrm{g} / \mathrm{L})$ ingredients: proteose peptone (10), beef extract (10), yeast extract (5), dextrose (20), polysorbate 80 (1), ammonium citrate (2), sodium acetate (5), magnesium sulfate (0.1), manganese sulfate (0.05), and, dipotassium phosphate (2).

\section{Fermentation Experiments}

Two sets of batch fermentations were carried out using serum bottles of $200 \mathrm{~mL}$ total volume. The working volume of the serum bottles was $100 \mathrm{~mL}$. The serum bottles were first filled with $90 \%(\mathrm{v} / \mathrm{v})$ bio-waste and then sealed with rubber stoppers and aluminum crimps. The sealed bottles were sparged with nitrogen gas for $5 \mathrm{~min}$ to ensure anaerobic conditions. The batch fermentations were inoculated with $10 \%(\mathrm{v} / \mathrm{v})$ of exponentially growing inoculum at mesophilic $\left(37^{\circ} \mathrm{C}\right)$ and stationary conditions for $48 \mathrm{~h}$. Control bottles contained only
TABLE 2 | List of treatments for the first batch fermentation set.

\begin{tabular}{llcc}
\hline $\begin{array}{l}\text { Experimental } \\
\text { set }\end{array}$ & Substrate & L. delbrueckii & pH adjustment \\
\hline i & Bio-waste 1 & - & - \\
ii & Bio-waste 1 & $\checkmark$ & - \\
iii & Bio-waste 1 & $\checkmark$ & $\checkmark$ \\
iv & Bio-waste 1 & - & $\checkmark$ \\
v & Bio-waste 2 & - & - \\
vi & Bio-waste 2 & $\checkmark$ & - \\
vii & Bio-waste 2 & $\checkmark$ & $\checkmark$ \\
viii & Autoclaved bio-waste & - & - \\
ix & Autoclaved bio-waste & $\checkmark$ & - \\
x & Autoclaved bio-waste & $\checkmark$ & $\checkmark$ \\
\hline
\end{tabular}

bio-waste (no inoculation with $L$. delbrueckii) were always prepared to define the production of lactic acid from the indigenous microbiome.

Regarding the first set of experiments, in addition to inoculation with $L$. delbrueckii, $\mathrm{pH}$ adjustment, substrate autoclavation and seasonality were also investigated. The $\mathrm{pH}$ value of the fermentation broth was adjusted to 6.2 using an $8 \mathrm{M} \mathrm{NaOH}$ solution before starting the batch experiment. The autoclavation was carried out at $121^{\circ} \mathrm{C}$ for $20 \mathrm{~min}$. Once the bottles cooled down and pressured dropped, the fermentation experiments were started. Due to the fact that the urban bio-waste can have different physicochemical characteristics at different periods, sampling was conducted at different collection dates to investigate the effect of seasonality. Exactly the same treatments including autoclavation, adjusting the $\mathrm{pH}$, and adding L. delbrueckii were performed the same for both bio-wastes. The experiments lasted $48 \mathrm{~h}$. The overall plan of the first experiment is given in Table 2.

The effect of enzymatic hydrolysis was the main focus of the second experiment. Cellulase (20 U/gTS) and $\beta$-glucosidase (10 $\mathrm{U} / \mathrm{gTS}$ ) were employed to release the sugar units in a buffer system with $\mathrm{pH}$ of 4.5 . The enzymatic hydrolysis experiments were conducted at shaken incubator $(150 \mathrm{rpm})$ at mesophilic conditions $\left(37^{\circ} \mathrm{C}\right)$ for $36 \mathrm{~h}$. In the experimental sets in which L. delbrueckii was added, the inoculation took place after the end of enzymatic hydrolysis and the bottles were moved to stationary conditions. In the sets in which the $\mathrm{pH}$ was adjusted, inoculation and $\mathrm{pH}$ adjustment took place right after the end of enzymatic hydrolysis; as the optimal $\mathrm{pH}$ of $L$. delbrueckii is different compared to the value needed for enzymes. As the optimal temperature of enzymes $\left(55^{\circ} \mathrm{C}\right)$ is different compared to the examined temperature level for fermentation tests $\left(37^{\circ} \mathrm{C}\right)$, batch tests were prepared at thermophilic conditions for $2 \mathrm{~h}$ in the shaken incubator (150 rpm) containing enzymes. After $2 \mathrm{~h}$, the bottles were placed back in the mesophilic stationary incubator. When the bottles reached mesophilic temperature, they were inoculated with $10 \%(\mathrm{v} / \mathrm{v})$ L. delbrueckii and the total experimental duration was $72 \mathrm{~h}$. The overall plan of the second experiment is given in Table 3 . 
TABLE 3 | List of treatments for the second batch fermentation set, focusing on enzymatic hydrolysis.

\begin{tabular}{|c|c|c|c|c|}
\hline Exp. & Substrate & L. delbrueckii & pH adjustment & Temperature \\
\hline$x i$ & Bio-waste & - & - & $37^{\circ} \mathrm{C}$ \\
\hline xii & Bio-waste & Added after $36 \mathrm{~h}$ & - & $37^{\circ} \mathrm{C}$ \\
\hline xiii & Bio-waste & Added after $36 \mathrm{~h}$ & $\checkmark$ & $37^{\circ} \mathrm{C}$ \\
\hline xiiv & Autoclaved bio-waste & - & - & $37^{\circ} \mathrm{C}$ \\
\hline xiv & Bio-waste & Added after $2 \mathrm{~h}$ & - & $55^{\circ} \mathrm{C}$ for $2 \mathrm{~h}$ \\
\hline$x v$ & Bio-waste & Added after $2 \mathrm{~h}$ & $\checkmark$ & $55^{\circ} \mathrm{C}$ for $2 \mathrm{~h}$ \\
\hline$x v i$ & Autoclaved bio-waste & Added after $2 \mathrm{~h}$ & - & $55^{\circ} \mathrm{C}$ for $2 \mathrm{~h}$ \\
\hline
\end{tabular}

\section{Analytical Methods}

Total solids (TS), volatile solids (VS), ash, Chemical Oxygen Demand (COD), ammonia nitrogen, total nitrogen were determined as described in Standard Methods (APHA, 2005). $\mathrm{pH}$ was measured with Metrohm $744 \mathrm{pH}$ meter. The content of trace elements in the bio-waste was measured using inductively coupled plasma with optical emission spectrometry (ICP-OES). Volatile fatty acids (VFA) concentrations were measured using GC-TRACE 1300 equipped with a Flame Ionization Detector (FID). A specific amount of sample $(1 \mu \mathrm{L})$ was automatically injected by the Thermo AI/AS 1310 Series Autosampler. Chromatographic separation was achieved on Agilent J \&W GC capillary Column (Length $30 \mathrm{~m}$, Diam. $0.530 \mathrm{~mm}$, Film thickness $1.50 \mu \mathrm{m}$, Temp limits from $40^{\circ} \mathrm{C}$ to $250^{\circ} \mathrm{C}$ ). The initial column temperature was set to $40^{\circ} \mathrm{C}$ for $6 \mathrm{~min}$ and then, was raised by $20^{\circ} \mathrm{C} / \mathrm{min}$ to $200^{\circ} \mathrm{C}$. The final temperature was held for $6 \mathrm{~min}$ and the total run-time was $20 \mathrm{~min}$, with Helium as the carrier gas. Total sugar determination was performed according to the NREL protocol for determination of structural carbohydrates in biomass (Sluiter et al., 2010). Xylose, glucose, succinic acid, lactic acid, formic acid, acetic acid, and ethanol were all detected and quantified using high performance liquid chromatography, HPLC. The HPLC (Agilent) had a refractive index detector (detection of sugars, VFAs and ethanol) and a Bio-Rad Aminex HPX-87H column $(300 \times 7.8 \mathrm{~mm})$ with $0.04 \mathrm{M}$ $\mathrm{H}_{2} \mathrm{SO}_{4}$ as eluent. The flow rate was set to $0.6 \mathrm{~mL} \mathrm{~min}^{-1}$ with column oven temperature set to $63.5^{\circ} \mathrm{C}$ (Alvarado-Morales et al., 2015). The overall yield of lactic acid was calculated based on gram produced lactic acid per gram of available total sugars. Maximum production rate was also calculated as mass of lactic acid produced at the middle of exponential phase, per volume of fermentation broth in time unit (hours) (Demichelis et al., 2017).

\section{Statistical Analysis}

One-way analysis of Variance followed by Tukey test $(p<0.05)$ was applied to reveal significant differences among the Experimental measurements. All statistical analyses were performed using the software SPSS Statistics, version 17.

\section{RESULTS AND DISCUSSION}

\section{Effect of Bio-Augmentation}

In control experiment without bio-augmentation, after $48 \mathrm{~h}$ a large part of the available sugars (43\%) and $100 \%$ of soluble glucose were fermented to lactic acid (Figure 1Ai). By inoculating $L$. delbrueckii, lactic acid production was slightly improved by $16 \%$ (Figure 1Aii). Although the microbial analysis of bio-waste was not performed in the current study, it is well-known that Lactobacilli are present in households and fresh organic residues (Mayrhofer et al., 2006; Partanen et al., 2010). According to the literature (Probst et al., 2013), 90\% of the bacterial community in food waste was LAB, mainly represented by Lactobacilli (70\%). Moreover, it was previously identified that Lactobacillus plantarum, Lactobacillus brevis, and their closest relatives Lactobacillus mudanjiangensis, Lactobacillus yonginensis, Lactobacillus paucivorans, Lactobacillus malefermentans, and Lactobacillus mixtipabuli are also among the most dominant bacteria in food wastes (Probst et al., 2013). In accordance, the co-lonization of $\mathrm{LAB}$ in the municipal bio-waste was indirectly shown in the current study. Specifically, the non-bio-augmented fermentation experiments led to a lactic acid concentration of $13.88 \pm 0.4$ $\mathrm{g} / \mathrm{L}$ in the final broth (Table 4), indicating the presence of fermentative LAB in the bio-waste. These results show that the natural microbiota is able to produce lactic acid without further microbial invasion.

A yield of $0.47 \mathrm{~g} / \mathrm{g}_{\text {total sugars }}$ was achieved using $L$. delbrueckii as the bio-augmentation bacterium in non-adjusted $\mathrm{pH}$ (Table 4), while in control samples the yield was 0.44 $\mathrm{g} / \mathrm{g}_{\text {total sugars. }}$. Despite the initial $\mathrm{pH}$ of the non-bio-augmented experiment was low $(\mathrm{pH}=4.9)$ due to acidic bio-waste, the final lactic acid titer was $13.88 \pm 0.4 \mathrm{~g} / \mathrm{L}$ (Exp. i). In contrast, the final titer was significantly boosted by $17 \%$ when the $\mathrm{pH}$ was adjusted to 6.2 for lactic acid fermentation (Exp. iv).

\section{Effect of pH Adjustment}

In both bio-wastes, adjusting $\mathrm{pH}$ had a significant effect $(p<$ 0.01 ) on lactic acid production. As shown in Figures 1A,B, there was a significant increase of lactic acid production in both biowastes, although the final titer of lactic acid was higher in the first bio-waste. Independently from $\mathrm{pH}$ adjustment, the entire 


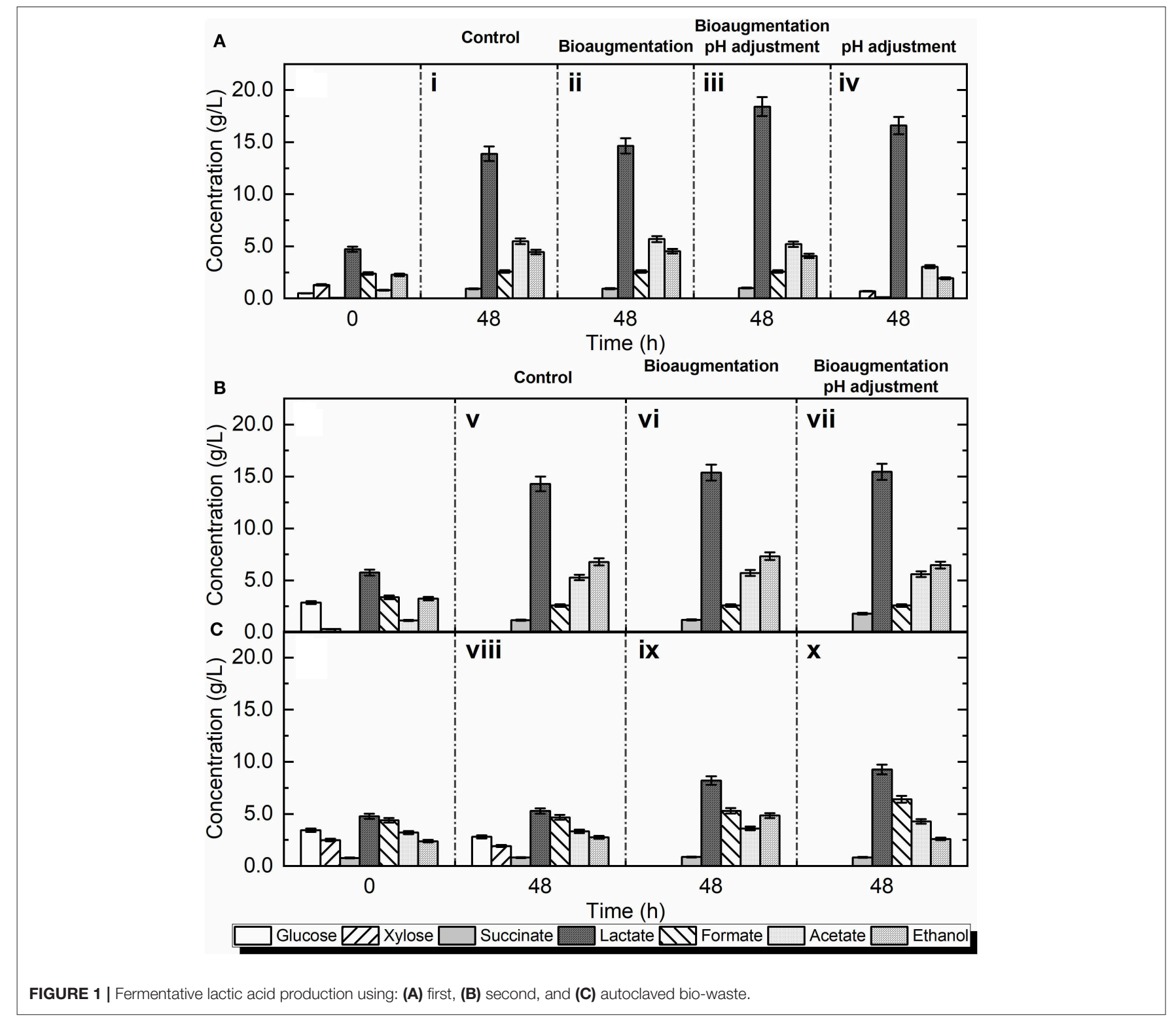

amount of soluble glucose was used by the microorganisms. After $48 \mathrm{~h}$ of fermentation, the concentration of lactic acid reached the peak of $18.4 \pm 0.2 \mathrm{~g} / \mathrm{L}$ in the first bio-waste (Exp. iii) and $15.59 \pm 0.2 \mathrm{~g} / \mathrm{L}$ in the second bio-waste (Exp. vii). When the inoculation with $L$. delbrueckii was tested without $\mathrm{pH}$ adjustment, an insignificant effect $(p>0.05)$ compared to the non-bioaugmented test was defined. Thus, $\mathrm{pH}$ adjustment is helpful to achieve high performance when $L$. delbrueckii is used as bioaugmentation inoculum.

Furthermore, the effect of adjusting $\mathrm{pH}$ without adding exogenous strains (Exp. iv) was investigated (Table 2). Results showed that the $\mathrm{pH}$ adjustment at the beginning of fermentation could also drive the lactic acid production at high levels (16.59 $\pm 0.4 \mathrm{~g} / \mathrm{L}$ ), indicating that indigenous microorganisms could be favored at a $\mathrm{pH}$ of 6.2 .
When the inoculation with $L$. delbrueckii was examined without $\mathrm{pH}$ adjustment (Exp. ii), an insignificant impact $(p>$ $0.05)$ compared to the control test was defined. It is indicated that L. delbrueckii could not settle and compete with the indigenous microcosm that was adapted to the more acidic conditions. In contrast, at the bio-augmentation tests in which the $\mathrm{pH}$ was adjusted (Exp. iii), the highest titer $(18.41 \pm 0.1 \mathrm{~g} / \mathrm{L})$ was recorded. Specifically, at the desired $\mathrm{pH}$ conditions the inoculation with $L$. delbrueckii improved the production by $32 \%$ compared to the non-bio-augmented fermentation. At the end of Exp. iii, a mixture of D-LA and L-LA (60:40) was revealed.

Regarding the second bio-waste, the inoculation with $L$. delbrueckii (Exp. vi and vii) led to slightly higher lactic acid compared to the control (Exp. v) (Figure 1B). Lactic acid yields of $0.46-0.47 \mathrm{~g} / \mathrm{g}_{\text {total sugars }}$ were achieved in the bio-augmented 
TABLE 4 | Lactic acid yield, titer and productivity.

\begin{tabular}{llccc}
\hline Exp. & Substrate & $\mathbf{Y}_{\text {LA }}\left(\mathbf{g} / \mathbf{g}_{\text {total sugars }}\right)$ & Titer (g/L) & Productivity (g/L/h) \\
\hline & Bio-waste 1 & 0.44 & $13.88 \pm 0.4$ & 1.91 \\
ii & Bio-waste 1 & 0.47 & 0.5 & 2.04 \\
iii & Bio-waste, 1 & 0.66 & $18.41 \pm 0.1$ & $16.59 \pm 0.4$ \\
iv & Bio-waste, 1 & 0.56 & $14.29 \pm 0.4$ & 2.85 \\
v & Bio-waste, 2 & 0.41 & $15.38 \pm 0.3$ & 1.78 \\
vi & Bio-waste, 2 & 0.46 & $15.45 \pm 0.1$ & 2.01 \\
vii & Bio-waste, 2 & 0.47 & $8.21 \pm 0.06$ & \\
ix & Autoclaved bio-waste & 0.16 & $9.27 \pm 0.30$ &
\end{tabular}

For explanation of the different experiments the reader is referred to Figure 1.

samples, while the control test was associated with a value of

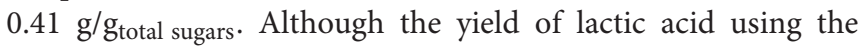
second bio-waste was lower than the first one, the difference was not significant $(p>0.05)$. The slight difference can be a result of ingredients variations through the waste collection or pulping process efficiency, which can consequently result in less free sugars. In agreement with the results of the first experiment, ethanol and acetic acid were the major by-products of mixed culture fermentation of $L$. delbrueckii and indigenous microorganisms of bio-waste. Figure 1B indicates that when $L$. delbrueckii was used as the inoculum the concentration of acetic acid and ethanol was increased to $5.71 \pm 0.02$ and $7.32 \pm 0.09$ $\mathrm{g} / \mathrm{L}$, respectively.

In both bio-augmented and non-bio-augmented tests, formic acid concentrations were decreased. Formic acid could be converted by the formate-hydrogen lyase into $\mathrm{H}_{2}$ and $\mathrm{CO}_{2}$ (Waligórska, 2012; Bastidas-Oyanedel et al., 2015) a reaction which utilizes protons and hence, can give an explanation on $\mathrm{pH}$ increase of the $\mathrm{pH}$ of the medium (Vivijs et al., 2015). The produced formic acid can be reimported in the cell through the FocA channel and become disproportionate to $\mathrm{CO}_{2}$ and $\mathrm{H}_{2}$ by the membrane-associated FHL complex (Sawers, 2005; Lü et al., 2012; Beyer et al., 2013). This complex includes the formate dehydrogenase $\mathrm{H}$ (FDH-H), a selenoprotein which carries a molybdenum cofactor, and hydrogenase 3, a nickel-containing protein complex (Bagramyan and Trchounian, 2003); explaining the formic acid degradation.

Figures 1A,B depict that in both inoculated bio-wastes with $L$. delbrueckii (ii, vi) and the control set (i, v), acetic acid and ethanol were the main by-products. Although in homofermentative strains as $L$. delbrueckii, glucose is catabolized via the EMP pathway with normally lactic acid as the only product, these strains can shift to mixed acid fermentation, resulting in acetic acid and ethanol (Endo and Dicks, 2014). The change to mixed acid fermentation can be the result of restriction of carbon, alteration in oxygen concentration or low growth rate, in which these strains still use the EMP but the end-products are altered (Goel et al., 2012; Bosma et al., 2017). Thus, the high production of by-products can be attributed to $L$. delbrueckii and native microflora co-existence. Besides acetic acid and ethanol, butyric and propionic acid by, respectively, $0.016 \pm 0.2$ and $0.003 \pm$ $0.09 \mathrm{~g} / \mathrm{L}$ were the main by-products, which are in agreement with previous studies (Li et al., 2018; Yousuf et al., 2018).

\section{Effect of Autoclavation}

When autoclavation was conducted in the control experiment without addition of $L$. delbrueckii (Exp. viii), no lactic acid production was detected (Figure 1C). In autoclaved bio-waste with $L$. delbrueckii, the yield was $0.16 \mathrm{~g} / \mathrm{g}_{\text {total sugars }}$ which is markedly lower than the same treatment for non-autoclaved bio-waste. Similarly to the previous tests, the major endproducts were ethanol and acetic acid. Nevertheless, the concentration of by-products was markedly lower in comparison with previous treatments, which can be explained by the absence of indigenous active microorganisms in bio-waste due to autoclavation. Regarding end-products, $\mathrm{LAB}$ are able to produce more diverse end-products when grown on carbon sources others than glucose (Papagianni, 2012; Holzapfel and Wood, 2014). Compared with the non-autoclaved (Exp. iii and vii), formic acid was raised when the $\mathrm{pH}$ was adjusted (Exp. x). All heterofermentative LAB encompass a two-domain aldehyde/alcohol dehydrogenase enzyme for the production of ethanol (Zheng et al., 2015). Some homofermentative species also encompass this enzyme, in which they also contain a pyruvateformic acid lyase (PFL) for the anaerobic conversion of pyruvate into acetyl-CoA and formic acid, which enzyme is not found in the heterofermentative LAB. Homofermentative LAB include Enterococcaceae, Streptococcaceae, and several Lactobacillaceae, while heterofermentation is found in species of Lactobacillaceae and Leuconostocaceae (Franz et al., 2014).

Figure 1C depicts the concentration of the fermentation products with $\mathrm{pH}$ adjustment and substrate sterilization (Exp. $\mathrm{x}$ ). The maximum yield of lactic acid at adjusted $\mathrm{pH}$ was 0.22 $\mathrm{g} / \mathrm{g}_{\text {total sugars }}$, while the yield in samples without $\mathrm{pH}$ adjustment was $0.16 \mathrm{~g} / \mathrm{g}_{\text {total sugars }}$ (Table 4). In comparison with nonautoclaved bio-wastes, the overall yield of lactic acid was lower in the autoclaved samples. Though adjusting the $\mathrm{pH}$ in autoclaved bio-waste could enhance the lactic acid yield, the overall result was considerably lower than the outcome of the most efficient not sterilized bio-waste treatment (Exp. iii). In addition, the low lactic 
acid yield is in accordance with the increased concentrations of by-products (i.e., acetic acid, ethanol, butyric acid and propionic acid). Thus, a significant portion of available sugars was not used for the production of the targeted molecule.

It is worth mentioning that the amount of free sugars in autoclaved bio-waste was higher than in the non-sterile biowaste. In non-autoclaved bio-waste, xylose was not detected, while a concentration of $2.4 \pm 0.06 \mathrm{~g} / \mathrm{L}$ was available at time 0 in autoclaved bio-waste. The high pressure and temperature during autoclavation could have led to hydrolysis of complex sugars that were not easily available for the microorganisms before the pretreatment.

In this study, autoclavation was applied to boost the release of free monosaccharides for the fermentative microbes. However, the conditions to achieve sterilization $\left(121^{\circ} \mathrm{C}\right.$ at $100 \mathrm{kPa}$ for $20 \mathrm{~min}$ ) did not have a markedly positive impact, not even when L. delbrueckii was injected in the sterile environment and adjusted pH. It is clearly shown that the bio-waste microcosm contained adapted members to the acidic environment and they could not be replaced by pure culture bio-augmentation in order to metabolize the complex carbohydrates. Moreover, mixed cultures fermentation have shown in numerous cases to be more robust compared to mono-culture fermentations (John et al., 2006; Nancib et al., 2009; Cui et al., 2011). Similar outcome was also concluded in with previous study using food waste in combined fermentation and chemical processes to produce highquality poly-L-lactate (Sakai et al., 2004). Since autoclavation is an energy intensive and a costly process, its usage at industrial scale is hardly economically feasible (Li et al., 2014; Pleissner et al., 2017). Thus, conditions without autoclavation could both reduce costs and simplify the process and at the same time result in higher amount of lactic acid compared to autoclaved condition. Therefore, this study indicates that autoclavation was not a viable pretreatment method for lactic acid production.

\section{Separate Hydrolysis and Fermentation}

To improve substrate's digestibility and product yield, enzymatic hydrolysis was evaluated as an extra pretreatment step (AcevesLara et al., 2008). Hydrolysis was performed for $36 \mathrm{~h}$ and subsequently, the fermentation took $36 \mathrm{~h}$. The amount of released glucose due to the addition of cellulase and $\beta$-glucosidase reached a maximum value of $18.08 \pm 0.9 \mathrm{~g} / \mathrm{L}$ at $36 \mathrm{~h}$ (Figure 2A). Meanwhile, a slight increase in xylose concentration $(2.64 \pm 0.1$ $\mathrm{g} / \mathrm{L}$ ) was observed during the enzymatic hydrolysis. Arabinose also increased during the enzymatic hydrolysis to $4.86 \pm 0.2$ $\mathrm{g} / \mathrm{L}$. Indeed, the cellulosic and hemicellulosic fractions of biowaste can be completely converted by enzymatic hydrolysis into their constituent monosaccharides, arabinose and xylose; and subsequently, the released monosaccharides can be used for fermentative lactic acid production (Marques et al., 2008).

The results of enhanced lactic acid titers after enzymatic hydrolysis are in agreement with previous studies. One example is increased production of lactic acid from recycled paper sludge (RPS) with Lactobacillus rhamnosus by enzymatic pretreatment (Marques et al., 2008). In the RPS study, a mixture of two commercial enzyme preparations (cellulolytic and xylanolytic) were used to hydrolyse the substrate. Likewise, in another study from broken rice by L. delbrueckii strain JCM1106, starch was gradually hydrolyzed to glucose and then converted to lactic acid (Bagramyan and Trchounian, 2003).

Additionally, in the current study bio-waste was used along with enzymes to investigate the process performance in the presence of the natural microbial community of bio-waste (Figure 2B, Exp. xi). A production rate of $2.87 \mathrm{~g} / \mathrm{L} / \mathrm{h}$ and yield of $0.60 \mathrm{~g} / \mathrm{g}_{\text {total sugars }}$ (Exp. xi) was achieved, which compared to the experiments without enzymes (Exp. i, v) and at the same fermentation conditions the yield was increased by 36 and $46 \%$, respectively (Table 5). This is very important as the utilization of microbes with high production rate can decrease the need for prolonged fermentation times. After $36 \mathrm{~h}$ of fermentation most of the soluble glucose and xylose were utilized by the indigenous microbes (Figure 2B) and L. delbrueckii (Figure 2C). In contrast, the released arabinose after enzymatic hydrolysis was not used by the microorganisms (Exp. xi and xii). The yield of lactic acid in Exp. xii was $0.725 \mathrm{~g} / \mathrm{g}_{\text {total sugars }}$ which compared to the same conditions without enzymes (Exp. i and vi) was increased by 52 and 55\%, respectively (Table 5). The obtained result is higher than previously achieved yields (Yousuf et al., 2018).

The combined effect of $\mathrm{pH}$ adjustment with $L$. delbrueckii bio-augmentation and enzymatic hydrolysis was also evaluated (Figure 2D; Exp. xiii). Regarding monomeric sugars, glucose and xylose were completely utilized by the microorganisms. In contrast, arabinose was increased during the enzymatic hydrolysis, but was not used by the microbes in the rest of the fermentation. This indicates that both $L$. delbrueckii and the autochthonous microcosm cannot fully utilize arabinose. According to the literature most of the LAB does not utilize arabinose, while L. buchneri and L. kefiri are able to utilize this pentose (Pot et al., 2014).

The concentration of lactic acid was slightly increased during the hydrolysis period and after inoculation with $L$. delbrueckii there was a dramatic increase in lactic acid concentration. Specifically, the maximum titer of lactic acid $19.73 \pm 0.9 \mathrm{~g} / \mathrm{L}$ was achieved after $48 \mathrm{~h}$ and then, started to decrease. The degradation of lactic acid can occur by the autochthonous microorganisms of bio-waste. According to literature, an isolated L. buchneri strain from maize silage was appraised for its potential as a bacterial inoculant to reduce the amount of lactic acid and increase the amount of acetic acid in silage (Driehuis et al., 1999). The degradation of lactic acid under anoxic conditions was also evaluated in a previous study (Oude Elferink et al., 2001) revealing that L. buchneri and L. parabuchneri could be responsible for this action. These strains were able to convert one mole of lactic acid to 0.5 mole of acetic acid, 0.5 mole of 1 , 2 propanediol, and low concentrations of ethanol.

The maximum production rate of $3.13 \mathrm{~g} / \mathrm{L} / \mathrm{h}$ was achieved in the bio-augmented samples in adjusted $\mathrm{pH}$. Moreover, the rate of lactic acid production in $\mathrm{pH}$-adjusted samples was $50 \%$ faster than non-adjusted samples, which is a great advantage in industrial scale applications. The yield of lactic acid production in these samples (Exp. xiii) was $0.72 \mathrm{~g} / \mathrm{g}_{\text {total sugars }}$ which showed a significant difference $(p<0.01)$ compared to non-adjusted $\mathrm{pH}$ (Exp. xii). Geobacillus stearothermophilus secreting extracellular amylases was used to convert starch from raw potato into lactic 


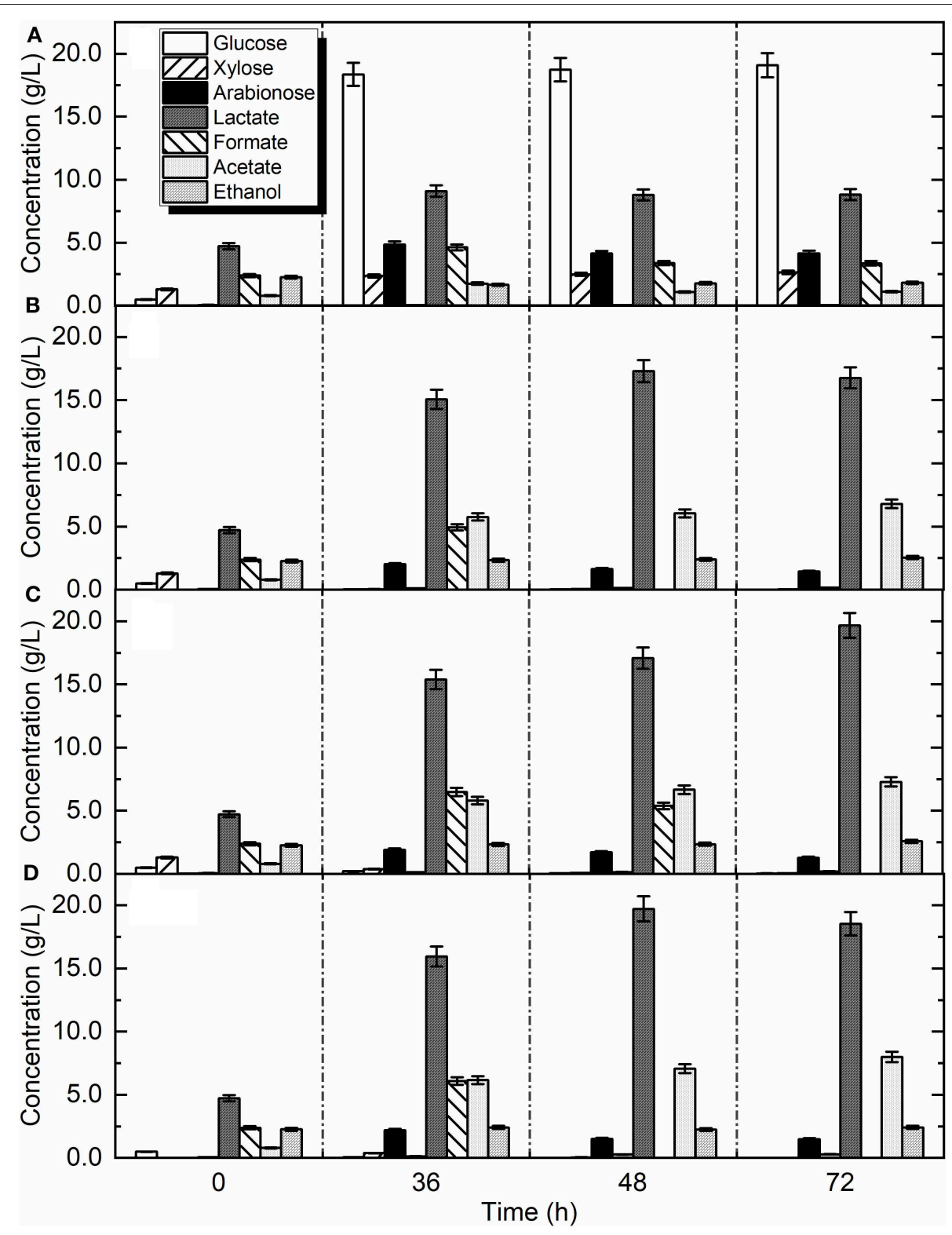

FIGURE 2 | Product and substrate profile over time in: (A) autoclaved bio-waste with enzymes without bio-augmentation and pH adjustment (control), (B) bio-waste with enzymes without bio-augmentation and without pH adjustment (Exp. xi), (C) bio-waste with enzymes with $L$. delbrueckii and without pH adjustment (Exp. xii), (D) bio-waste with enzymes with L. delbrueckii, and with $\mathrm{pH}$ adjustment (Exp. xiii).

TABLE 5 | Lactic acid yield, titer and productivity for the hydrolysis and simultaneous saccharification and fermentation set.

\begin{tabular}{|c|c|c|c|c|c|c|}
\hline Exp. & Substrate & $\mathrm{pH}$ adjustment & Temperature & Titer (g/L) & Productivity (g/L/h) & $Y_{\text {LA }}(g / g)$ \\
\hline$x i$ & Bio-waste & - & $37^{\circ} \mathrm{C}$ & $17.3 \pm 0.8$ & 2.87 & 0.6 \\
\hline xii & Bio-waste & - & $37^{\circ} \mathrm{C}$ & $19.67 \pm 0.9$ & 2.96 & 0.72 \\
\hline xiii & Bio-waste & $\checkmark$ & $37^{\circ} \mathrm{C}$ & $19.73 \pm 0.9$ & 3.13 & 0.72 \\
\hline xiv & Bio-waste & - & $55^{\circ} \mathrm{C}$ for $2 \mathrm{~h}$ & $17.26 \pm 1.09$ & 1.74 & 0.60 \\
\hline$x V$ & Bio-waste & $\checkmark$ & $55^{\circ} \mathrm{C}$ for $2 \mathrm{~h}$ & $17.57 \pm 2.3$ & 1.78 & 0.61 \\
\hline xvi & Autoclaved bio-waste & $\checkmark$ & $55^{\circ} \mathrm{C}$ for $2 \mathrm{~h}$ & $18.06 \pm 0.1$ & 1.85 & 0.64 \\
\hline
\end{tabular}


acid (Smerilli et al., 2015), achieving yield and productivity of $0.66 \mathrm{~g} / \mathrm{g}$ starch and $1.8 \mathrm{~g} / \mathrm{L} / \mathrm{h}$, respectively. Overall, the used enzymes prior to lactic acid fermentation led to a yield of $0.72 \mathrm{~g} / \mathrm{g}_{\text {total sugars }}$ which was the highest achieved in the present study and was $9 \%$ higher than the direct production of lactic acid without the extra step of enzymatic hydrolysis. Nevertheless, the achieved yield was still lower than literature targeted values $\left(0.92 \mathrm{~g} / \mathrm{g}_{\text {total sugars }}\right)$ to achieve in economic feasibility (Kwan et al., 2018). Considering that hydrolysis can represent almost $20 \%$ of the operating costs during LA production, it is clearly indicated that hydrolysis efficiency has to be improved in order to compensate the needed cost. In addition, further optimization of operational parameters (i.e., temperature, reactor configurations) and metrics (i.e., byproducts elimination, adaptation to inhibitors) is needed before scale-up operation.

\section{Simultaneous Saccharification and Fermentation}

Figure $3 \mathrm{~A}$ shows the effect of $L$. delbrueckii as the inoculum without $\mathrm{pH}$ adjustment during SSF (Exp. xiv). The maximum production rate at the end of exponential phase was $1.74 \mathrm{~g} / \mathrm{L} / \mathrm{h}$ and the maximum amount of lactic acid was $17.26 \pm 1.09 \mathrm{~g} / \mathrm{L}$ with a yield of $0.60 \mathrm{~g} / \mathrm{g}_{\text {total sugars, }}$ which was $19 \%$ lower than the yield applying separately the enzymatic hydrolysis (Exp. xii).

Since in SSF the enzymes and bio-waste were added together at $55^{\circ} \mathrm{C}$ for $2 \mathrm{~h}$, the hydrolysis of sugars took place during the first $2 \mathrm{~h}$ of operation. In accordance, the amount of free glucose increased in $2 \mathrm{~h}$ and reached a maximum amount of $16.43 \pm 0.1 \mathrm{~g} / \mathrm{L}$. Directly after inoculation, the microbes started to utilize the glucose and xylose. Compared to other studies on different strains such as L. rhamnosus on recycled paper sludge which was not able to consume free xylose (Marques

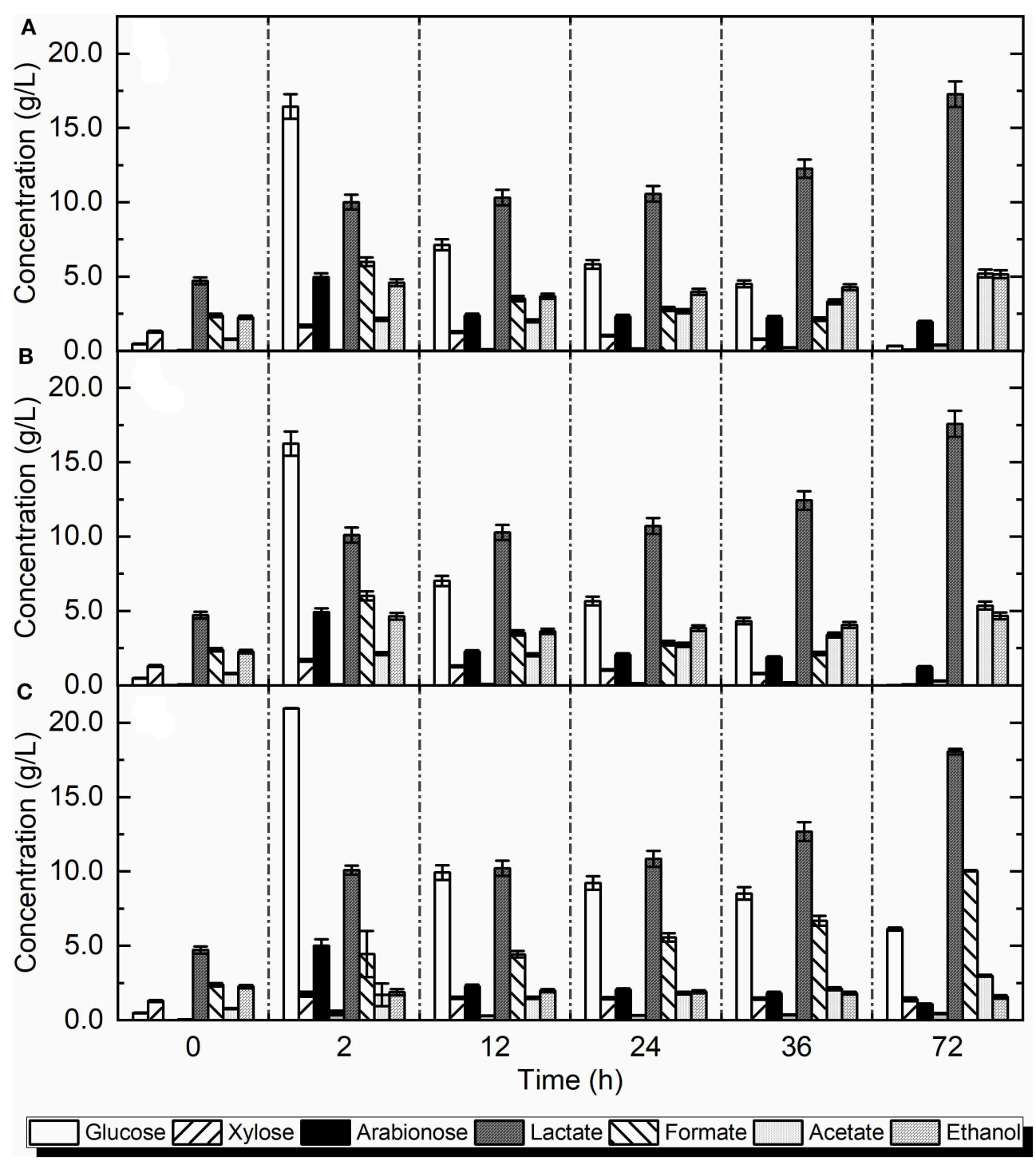

FIGURE 3 | Simultaneous saccharification and fermentation: (A) with L. delbrueckii, without pH adjustment (Exp. xiv), (B) with L. delbrueckii, with pH adjustment (Exp. xv), (C) using autoclaved bio-waste with L. delbrueckii, with pH adjustment (Exp. xvi). 
et al., 2008), L. delbrueckii and the indigenous microcosm showed strong ability to assimilate the pentose. Xylose can be converted via a heterofermentative pathway yielding high titers of acetic acid (Hofvendahl and Hahn-Hägerdal, 2000; Marques et al., 2008), which is in agreement with the results of the present study in which acetic acid was the main by-product. Ethanol, propionic and butyric acid were the other detected end-products in the final broth. The results are in agreement with other studies using L. delbrueckii along with SSF on lactic acid production from alfalfa fiber (Sreenath et al., 2001). In the latter study, L. plantarum and L. delbrueckii strains produced 0.464 and $0.354 \mathrm{~g}$ of lactic acid per $\mathrm{g}$ of dry matter of alfalfa fiber, respectively.

Figure 3B illustrates the impact of $L$. delbrueckii addition along with $\mathrm{pH}$ adjustment (Exp. xv). Since the concentration of lactic acid increased rapidly during the first $2 \mathrm{~h}$, it was concluded that the indigenous microorganisms of bio-waste could perform well at $55^{\circ} \mathrm{C}$ and there might be heat-adopted microorganisms in bio-waste because of the high temperatures of the waste collection sites. Thus, the higher temperature could have a positive impact on the lactic acid production rate. Although the optimum growth temperature for most $\mathrm{LAB}$ is $30-37^{\circ} \mathrm{C}$, many species have a very wide growth temperature range with upper temperature limit often around $45^{\circ} \mathrm{C}$ (Monteagudo et al., 1997; Pot et al., 2014; Bosma et al., 2017). Different species of particularly Lactobacilli such as L. delbrueckii are very thermo-tolerant and grow well up to around $50^{\circ} \mathrm{C}$ (Monteagudo et al., 1997; Bosma et al., 2017). This thermo-tolerance might explain the dramatic increase in lactic acid concentration during the 2 initial hours of SSF. The thermophilic range, which is optimal for the enzymes, was kept only for $2 \mathrm{~h}$ and subsequently was changed to mesophilic conditions (i.e., $37^{\circ} \mathrm{C}$ ). Moreover, the achieved production rate at the end of exponential phase was higher than the rate of $0.7 \mathrm{~g} / \mathrm{L} / \mathrm{h}$ achieved in other studies using L. delbrueckii as an inoculum and hydrolyzing food waste (Kim et al., 2003). In comparison with non-pH adjusted experiment (Exp. xiv), both concentration and yield of lactic acid increased during the SSF. However, the difference is insignificant compared to the non-adjusted $\mathrm{pH}(p>0.05)$. In general, the statistical analysis showed no significant differences among the SSF experiments $(p>0.05)$.

Figure 3C shows the effect of autoclavation along with $\mathrm{pH}$ adjustment, and addition of $L$. delbrueckii. The concentration of lactic acid markedly increased in the first $2 \mathrm{~h}$ and reached a maximum amount of $18.06 \pm 0.1 \mathrm{~g} / \mathrm{L}$ and a yield of 0.64

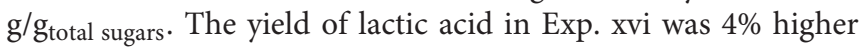
compared to Exp. xv (Table 5). The maximum production rate at the end of exponential phase was $1.85 \mathrm{~g} / \mathrm{L} / \mathrm{h}$, which was higher than the productivity of SSF from food waste using Lactobacillus strains which was $0.27-0.53 \mathrm{~g} / \mathrm{L} / \mathrm{h}$, with a yield of $0.14 \mathrm{~g} / \mathrm{g}_{\text {total sugars }}$ (Pleissner et al., 2017). The hydrolysis of carbohydrates took place in the first $2 \mathrm{~h}$ as indicated by the raise in soluble glucose, arabinose, and xylose. Among all of SSF experiments, the autoclavation had the highest concentration of available sugars $(27.71 \pm 0.2 \mathrm{~g} / \mathrm{L})$, while in non-autoclaved bio-waste the sugars were $23.09 \pm 0.17 \mathrm{~g} / \mathrm{L}$ (20\% lower). This can be attributed to the high pressure and temperature that contributed to the solubilization of biopolymers (Shet et al., 2018). Despite high released sugars content in SSF, the amount of lactic acid produced was not significantly higher than the samples without autoclavation $(p>0.05)$. Although the release of sugars increased with autoclavation, the lactic acid production was not increased, since the indigenous microbial community was inactivated and the inoculated strain was not able to metabolize the free sugars.

\section{CONCLUSIONS}

Overall, the present research demonstrates that lactic acid production can be achieved using bio-waste. Specifically, 0.65 $\mathrm{g} / \mathrm{g}_{\text {total sugars }}$ was produced when Lactobacillus delbrueckii was used as bio-augmentation inoculum reaching a final titer of more than $18.41 \pm 0.1 \mathrm{~g} / \mathrm{L}$ at a productivity of $2.85 \mathrm{~g} / \mathrm{L} / \mathrm{h}$. A semi-controlled natural fermentation with $\mathrm{pH}$ adjustment led to comparable value of $16.59 \pm 0.4 \mathrm{~g} / \mathrm{L}$ at a yield of $0.56 \mathrm{~g} / \mathrm{g}_{\text {total sugars }}$ utilizing the indigenous microcosm. Application of enzymatic hydrolysis and simultaneous saccharification and fermentation showed efficiencies equal to 0.72 and $0.64 \mathrm{~g} / \mathrm{g}_{\text {total sugars, }}$, respectively. The results obtained in the current research can be exploited to expand the utilization of bio-waste for lactic acid production.

\section{DATA AVAILABILITY STATEMENT}

The datasets generated for this study are available on request to the corresponding author.

\section{AUTHOR CONTRIBUTIONS}

PT set up bioreactors, collected samples, designed experiments, analyzed biochemical parameters, drafted, and revised the manuscript. MA-M designed experiments, analyzed biochemical parameters drafted, and revised the manuscript. SB set up bioreactors, monitored reactors performance, collected samples drafted, and revised the manuscript. EB designed experiments and revised the manuscript. IA designed and supervised experiments and revised the manuscript. All authors contributed to the article and approved the submitted version.

\section{ACKNOWLEDGMENTS}

We would like to thank the Copenhagen municipality for financial support and HCS Company to provide us with biopulp as a substrate for lab experiments. 


\section{REFERENCES}

Abdel-Rahman, M. A., Tashiro, Y., and Sonomoto, K. (2013). Recent advances in lactic acid production by microbial fermentation processes. Biotechnol. Adv. 31, 877-902. doi: 10.1016/j.biotechadv.2013.04.002

Aceves-Lara, C. A., Trably, E., Bastidas-Oyenadel, J. R., Ramirez, I., Latrille, E., and Steyer, J. P. (2008). Production de bioénergies à partir de déchets: exemples du biométhane et du biohydrogène. J. Soc. Biol. 202, 177-189. doi: 10.1051/jbio:2008020

Alvarado-Morales, M., Gunnarsson, I. B., Fotidis, I. A., Vasilakou, E., Lyberatos, G., and Angelidaki, I. (2015). Laminaria digitata as a potential carbon source for succinic acid and bioenergy production in a biorefinery perspective. Algal Res. 9, 126-132. doi: 10.1016/j.algal.2015.03.008

Alves de Oliveira, R., Komesu, A., Vaz Rossell, C. E., and Maciel Filho, R. (2018). Challenges and opportunities in lactic acid bioprocess designFrom economic to production aspects. Biochem. Eng. J. 133, 219-239. doi: 10.1016/j.bej.2018.03.003

American Public Health Association (2005). Standard Methods for the Examination of Water and Wastewater. Washington, DC: American Public Health Association.

Bagramyan, K., and Trchounian, A. (2003). Structural and functional features of formate hydrogen lyase, an enzyme of mixed-acid fermentation from Escherichia coli. Biochem. 68, 1159-1170. doi: 10.1023/B:BIRY.0000009129.18714.a4

Bastidas-Oyanedel, J. R., Bonk, F., Thomsen, M. H., and Schmidt, J. E. (2015). Dark fermentation biorefinery in the present and future (bio)chemical industry. Rev. Environ. Sci. Biotechnol. 14, 473-498. doi: 10.1007/s11157-01 5-9369-3

Beyer, L., Doberenz, C., Falke, D., Hunger, D., Suppmann, B., and Sawers, R. G. (2013). Coordination of FocA and pyruvate formate-lyase synthesis in escherichia coli demonstrates preferential translocation of formate over other mixed-acid fermentation products. J. Bacteriol. 195, 1428-1435. doi: 10.1128/JB.02166-12

Bosma, E. F., Forster, J., and Nielsen, A. T. (2017). Lactobacilli and pediococci as versatile cell factories - Evaluation of strain properties and genetic tools. Biotechnol. Adv. 35, 419-442. doi: 10.1016/j.biotechadv.2017.04.002

Cui, F., Li, Y., and Wan, C. (2011). Lactic acid production from corn stover using mixed cultures of Lactobacillus rhamnosus and Lactobacillus brevis. Bioresour. Technol. 102, 1831-1836. doi: 10.1016/j.biortech.2010.09.063

Demichelis, F., Pleissner, D., Fiore, S., Mariano, S., Navarro Gutiérrez, I. M., Schneider, R., et al. (2017). Investigation of food waste valorization through sequential lactic acid fermentative production and anaerobic digestion of fermentation residues. Bioresour. Technol. 241, 508-516. doi: 10.1016/j.biortech.2017.05.174

Driehuis, F., Oude Elferink, S. J. W. H., and Spoelstra, S. F. (1999). Anaerobic lactic acid degradation during ensilage of whole crop maize inoculated with Lactobacillus buchneri inhibits yeast growth and improves aerobic stability. J. Appl. Microbiol. 87, 583-594. doi: 10.1046/j.1365-2672.1999.00856.x

Endo, A., and Dicks, L. M. T. (2014). "Physiology of the LAB," in Lactic Acid Bacteria: Biodiversity and Taxonomy (John Wiley \& Sons), 13-30. doi: 10.1002/9781118655252.ch2

Franz, C. M. A. P., Endo, A., Abriouel, H., Van Reenen, C. A., Gálvez, A., and Dicks, L. M. T. (2014). "The genus Pediococcus," in Lactic Acid Bacteria: Biodiversity and Taxonomy (John Wiley \& Sons), 359-376. doi: 10.1002/9781118655252.ch21

Goel, A., Wortel, M. T., Molenaar, D., and Teusink, B. (2012). Metabolic shifts: a fitness perspective for microbial cell factories. Biotechnol. Lett. 34, 2147-2160. doi: 10.1007/s10529-012-1038-9

Hofvendahl, K., and Hahn-Hägerdal, B. (2000). Factors affecting the fermentative lactic acid production from renewable resources. Enzyme Microb. Technol. 26, 87-107. doi: 10.1016/S0141-0229(99)00155-6

Holzapfel, W. H., and Wood, B. J. B. (2014). Lactic Acid Bacteria: Biodiversity and Taxonomy. Chichester: John Wiley \& Sons, Ltd. doi: 10.1002/9781118 655252

John, R. P., Nampoothiri, K. M., and Pandey, A. (2006). Simultaneous saccharification and fermentation of cassava bagasse for L-(+)-lactic acid production using Lactobacilli. Appl. Biochem. Biotechnol. 134, 263-272. doi: 10.1385/ABAB:134:3:263
Kim, K., Il, Kim, W. K., Seo, D. K., Yoo, I. S., Kim, E. K., and Yoon, H. H. (2003). Production of lactic acid from food wastes. Appl. Biochem. Biotechnol. - Part A Enzym. Eng. Biotechnol. 107, 637-647. doi: 10.1385/ABAB:107:1-3:637

Kwan, T. H., Hu, Y., and Lin, C. S. K. (2018). Techno-economic analysis of a food waste valorisation process for lactic acid, lactide and poly(lactic acid) production. J. Clean. Prod. 181, 72-87. doi: 10.1016/j.jclepro.2018.01.179

Li, J., Zhang, W., Li, X., Ye, T., Gan, Y., Zhang, A., et al. (2018). Production of lactic acid from thermal pretreated food waste through the fermentation of waste activated sludge: effects of substrate and thermal pretreatment temperature. Bioresour. Technol. 247, 890-896. doi: 10.1016/j.biortech.2017.09.186

Li, T., Chen, X. B., Chen, J. C., Wu, Q., and Chen, G. Q. (2014). Open and continuous fermentation: products, conditions and bioprocess economy. Biotechnol. J. 9, 1503-1511. doi: 10.1002/biot.201400084

Li, Y., Zhang, Y., Sun, Y., Wu, S., Kong, X., Yuan, Z., et al. (2017). The performance efficiency of bioaugmentation to prevent anaerobic digestion failure from ammonia and propionate inhibition. Bioresour. Technol. 231, 94-100. doi: 10.1016/j.biortech,.2017.01.068

Lü, W., Du, J., Schwarzer, N. J., Gerbig-Smentek, E., Einsle, O., and Andrade, S. L. A. (2012). The formate channel FocA exports the products of mixed-acid fermentation. Proc. Natl. Acad. Sci. U.S.A. 109, 13254-13259. doi: 10.1073/pnas.1204201109

Marques, S., Santos, J. A. L., Gírio, F. M., and Roseiro, J. C. (2008). Lactic acid production from recycled paper sludge by simultaneous saccharification and fermentation. Biochem. Eng. J. 41, 210-216. doi: 10.1016/j.bej.2008.04.018

Mayrhofer, S., Mikoviny, T., Waldhuber, S., Wagner, A. O., Innerebner, G., FrankeWhittle, I. H., et al. (2006). Microbial community related to volatile organic compound (VOC) emission in household biowaste. Environ. Microbiol. 8, 1960-1974. doi: 10.1111/j.1462-2920.2006.01076.x

Monteagudo, J. M., Rodríguez, L., Rincón, J., and Fuertes, J. (1997). Kinetics of lactic acid fermentation by Lactobacillus delbrueckii grown on beet molasses. J. Chem. Technol. Biotechnol. 68, 271-276. doi: 10.1002/(SICI)1097-4660(199703)68:3\&lt;271::AID-JCTB640\&gt; 3.0.CO;2-9

Mora-Villalobos, J. A., Montero-Zamora, J., Barboza, N., Rojas-Garbanzo, C., Usaga, J., Redondo-Solano, M., et al. (2020). Multi-product lactic acid bacteria fermentations: a review. Fermentation 6, 1-21. doi: $10.3390 /$ fermentation 6010023

Nancib, A., Nancib, N., and Boudrant, J. (2009). Production of lactic acid from date juice extract with free cells of single and mixed cultures of Lactobacillus casei and Lactococcus lactis. World J. Microbiol. Biotechnol. 25, 1423-1429. doi: 10.1007/s11274-009-0029-z

Oude Elferink, S. J. W. H., Krooneman, E. J., Gottschal, J. C., Spoelstra, S. F., Faber, F., and Driehuis, F. (2001). Anaerobic conversion of lactic acid to acetic acid and 1,2-propanediol by Lactobacillus buchneri. Appl. Environ. Microbiol. 67, 125-132. doi: 10.1128/AEM.67.1.125-132.2001

Papagianni, M. (2012). Metabolic engineering of lactic acid bacteria for the production of industrially important compounds. Comput. Struct. Biotechnol. J. 3:e201210003. doi: 10.5936/csbj.201210003

Partanen, P., Hultman, J., Paulin, L., Auvinen, P., and Romantschuk, M. (2010). Bacterial diversity at different stages of the composting process. BMC Microbiol. 10:94. doi: 10.1186/1471-2180-10-94

Pleissner, D., Demichelis, F., Mariano, S., Fiore, S., Navarro Gutiérrez, I. M., Schneider, R., et al. (2017). Direct production of lactic acid based on simultaneous saccharification and fermentation of mixed restaurant food waste. J. Clean. Prod. 143, 615-623. doi: 10.1016/j.jclepro.2016.12.065

Pot, B., Felis, G. E., Bruyne, K., De, Tsakalidou, E., Papadimitriou, K., Leisner, J., et al. (2014). "The genus Lactobacillus," in Lactic Acid Bacteria: Biodiversity and Taxonomy (John Wiley \& Sons), 249-353. doi: 10.1002/9781118655252.ch19

Probst, M., Fritschi, A., Wagner, A., and Insam, H. (2013). Biowaste: a Lactobacillus habitat and lactic acid fermentation substrate. Bioresour. Technol. 143, 647-652. doi: 10.1016/j.biortech.2013.06.022

Sakai, K., Taniguchi, M., Miura, S., Ohara, H., Matsumato, T., and Shirai, Y. (2004). Making plastics from garbage a novel process for poly- L -lactate. J. Ind. Ecol. 7 , 63-74. doi: 10.1162/108819803323059406

Sawers, R. G. (2005). "Formate and its role in hydrogen production in Escherichia coli, in Biochem. Soc. Trans. 33, 42-46. doi: 10.1042/BST0330042

Shet, V. B., Varun, C., Aishwarya, U., Palan, A. M., Rao, S. U., Goveas, L. C., et al. (2018). Optimization of reducing sugars production from agro-residue 
coconut leaflets using autoclave-assisted $\mathrm{HCl}$ hydrolysis with response surface methodology. Agric. Nat. Resour. 52, 280-284. doi: 10.1016/j.anres.2018.09.015

Singhvi, M., Zendo, T., and Sonomoto, K. (2018). Free lactic acid production under acidic conditions by lactic acid bacteria strains: challenges and future prospects. Appl. Microbiol. Biotechnol. 102, 5911-5924. doi: 10.1007/s00253-018-9092-4

Sluiter, A., Hames, B., Ruiz, R., Scarlata, C., Sluiter, J., Templeton, D., et al. (2010). Determination of structural carbohydrates and lignin in biomass. Lab. Anal. Proced. Technical Report NREL/TP-510-42618.

Smerilli, M., Neureiter, M., Wurz, S., Haas, C., Frühauf, S., and Fuchs, W. (2015). Direct fermentation of potato starch and potato residues to lactic acid by Geobacillus stearothermophilus under non-sterile conditions. J. Chem. Technol. Biotechnol. 90, 648-657. doi: 10.1002/jctb.4627

Sreenath, H. K., Moldes, A. B., Koegel, R. G., and Straub, R. J. (2001). Lactic acid production from agriculture residues. Biotechnol. Lett. 23, 179-184. doi: 10.1023/A:1005651117831

Tang, J., Wang, X., Hu, Y., Zhang, Y., and Li, Y. (2016). Lactic acid fermentation from food waste with indigenous microbiota: effects of $\mathrm{pH}$, temperature and high OLR. Waste Manag. 52, 278-285. doi: 10.1016/j.wasman.2016. 03.034

Tashiro, Y., Matsumoto, H., Miyamoto, H., Okugawa, Y., Pramod, P., Miyamoto, H., et al. (2013). A novel production process for optically pure l-lactic acid from kitchen refuse using a bacterial consortium at high temperatures. Bioresour. Technol. 146, 672-681. doi: 10.1016/j.biortech.2013.07.102

Tian, H., Mancini, E., Treu, L., Angelidaki, I., and Fotidis, I. A. (2019). Bioaugmentation strategy for overcoming ammonia inhibition during biomethanation of a protein-rich substrate. Chemosphere 231, 415-422. doi: 10.1016/j.chemosphere.2019.05.140
Vivijs, B., Haberbeck, L. U., Mfortaw Mbong, V. B., Bernaerts, K., Geeraerd, A. H., Aertsen, A., et al. (2015). Formate hydrogen lyase mediates stationary-phase deacidification and increases survival during sugar fermentation in acetoin-producing enterobacteria. Front. Microbiol. 6:150. doi: $10.3389 /$ fmicb. 2015.00150

Waligórska, M. (2012). Fermentative hydrogen production - process design and bioreactors. Chem. Process Eng. Inz. Chem. i Proces. 33, 585-594. doi: 10.2478/v10176-012-0048-4

Yousuf, A., Bastidas-Oyanedel, J. R., and Schmidt, J. E. (2018). Effect of total solid content and pretreatment on the production of lactic acid from mixed culture dark fermentation of food waste. Waste Manag. 77, 516-521. doi: 10.1016/j.wasman.2018.04.035

Zheng, J., Ruan, L., Sun, M., and Gänzle, M. (2015). A genomic view of lactobacilli and pediococci demonstrates that phylogeny matches ecology and physiology. Appl. Environ. Microbiol. 81, 7233-7243. doi: 10.1128/AEM.02116-15

Conflict of Interest: The authors declare that the research was conducted in the absence of any commercial or financial relationships that could be construed as a potential conflict of interest.

Copyright (c) 2020 Tsapekos, Alvarado-Morales, Baladi, Bosma and Angelidaki. This is an open-access article distributed under the terms of the Creative Commons Attribution License (CC BY). The use, distribution or reproduction in other forums is permitted, provided the original author(s) and the copyright owner(s) are credited and that the original publication in this journal is cited, in accordance with accepted academic practice. No use, distribution or reproduction is permitted which does not comply with these terms. 